\title{
Arbo-Score: A Rapid Score for Early Identification of Patients with Imported Arbovirosis Caused by Dengue, Chikungunya and Zika Virus
}

\author{
Iacopo Vellere ${ }^{1}{ }^{\oplus}$, Filippo Lagi ${ }^{1,2}$, Michele Spinicci ${ }^{1,3}$, Antonia Mantella ${ }^{1}$, \\ Elisabetta Mantengoli ${ }^{2}$, Giampaolo Corti ${ }^{1,2} \mathbb{1}$, Maria Grazia Colao ${ }^{4}$, Federico Gobbi ${ }^{5}$, \\ Gian Maria Rossolini ${ }^{1,4}$, Alessandro Bartoloni ${ }^{1,3}(\mathbb{D}$ and Lorenzo Zammarchi 1,3,*(D) \\ 1 Department of Experimental and Clinical Medicine, University of Florence, 50134 Florence, Italy; \\ iacopo.vellere@unifi.it (I.V.); filippo.lagi@unifi.it (F.L.); michele.spinicci@unifi.it (M.S.); \\ antonia.mantella@unifi.it (A.M.); giampaolo.corti@unifi.it (G.C.); gianmaria.rossolini@unifi.it (G.M.R.); \\ alessandro.bartoloni@unifi.it (A.B.) \\ 2 Infectious and Tropical Diseases Unit, Careggi University Hospital, 50134 Florence, Italy; \\ mantengolie@aou-careggi.toscana.it \\ 3 Referral Centre for Tropical Diseases of Tuscany, Infectious and Tropical Diseases Unit, \\ Careggi University Hospital, 50134 Florence, Italy \\ 4 Clinical Microbiology and Virology Unit, Careggi University Hospital, 50134 Florence, Italy; \\ colaog@aou-careggi.toscana.it \\ 5 Department of Infectious/Tropical Diseases and Microbiology, IRCCS Sacro Cuore Don Calabria Hospital, \\ 37024 Negrar, Verona, Italy; federico.gobbi@sacrocuore.it \\ * Correspondence: lorenzo.zammarchi@unifi.it; Tel.: +39-0557949431
}

Received: 8 October 2020; Accepted: 2 November 2020; Published: 4 November 2020

Abstract: Background: Chikungunya (CHIKV), Dengue (DENV), and Zika (ZIKV) viruses present significant clinical and epidemiological overlap, making an accurate and rapid diagnosis challenging. Timely activation of preventive vector control measures is crucial to avoid outbreaks in non-endemic settings. Diagnosis is based on combination of serological and molecular assays which could be time consuming and sometimes disappointing. Methods: We report the results of a retrospective case-control study carried out at a tertiary teaching hospital in Italy, including all febrile subjects returning from tropical countries during the period 2014-2019. Controls were travelers with other febrile illnesses who tested negative in laboratory analysis for CHIKV, DENV, ZIKV arbovirosis. A score weighted on the regression coefficients for the independent predictors was generated. Results: Ninety patients were identified: 34 cases (22 DENV, 4 CHIKV, and 8 ZIKV) and 56 controls. According to our results, myalgia, cutaneous rash, absence of respiratory symptoms, leukopenia, and hypertransaminasemia showed the strongest association with arbovirosis. Combining these variables, we generated a scoring model that showed an excellent performance (AUC 0.93). The best cut-off ( $>=2$ ) presented a sensitivity of $82.35 \%$ and specificity of $96.43 \%$. Conclusion: A handy and simple score, based on three clinical data (myalgia, cutaneous rash and absence of respiratory symptoms) and two laboratory results (leukopenia and hypertransaminasemia), provides a useful tool to help diagnose arboviral infections and appropriately activate vector control measures in order to avoid local transmission.

Keywords: dengue; Zika; chikungunya; imported; timing; diagnosis; travelers; score

\section{Introduction}

Chikungunya (CHIKV), Dengue (DENV), and Zika (ZIKV) are three Aedes-borne viruses with significant clinical and epidemiological overlap associated with possible serological cross-reactivity 
between viruses belonging to the same family of Flavivirus, such as DENV and ZIKV, making an accurate and rapid diagnosis challenging [1-3]. During the last 50 years, many DENV outbreaks occurred, which has contributed to the spread of the virus worldwide [4]. Circulation of CHIKV was limited to the African and Asian regions until 2013, when it reached the Americas [5]. In 2007, the first ZIKV outbreak outside Asia and Africa occurred in the Yap State, Micronesia [6], and later, in 2015, the virus spread to Latin America [7].

These diseases have become a public health concern also in non-tropical countries due to an increasing number of imported infections [8]. The worldwide diffusion of competent vectors such as Aedes aegypti and Aedes albopictus allowed autochthonous transmission reaching the southern United States [9] and the Mediterranean basin [10-12]. Even though imported cases of ZIKV have decreased in the last two years [13], in 2019 autochthonous transmission was still registered in southern France [14]. Additionally, human-to-human modes of transmission are possible even in the absence of vectors, and concerns about transmission via blood transfusions and sexual intercourse are increasing [15-17].

Even though the initial clinical manifestations may be similar for the three arboviral infections, as well as for other febrile diseases commonly affecting travelers [18], the complications of these three infections are very different and specific and require targeted medical interventions. DENV could rapidly turn into a life-threatening shock and hemorrhagic syndrome. In this case, non-steroidal anti-inflammatory drugs and invasive procedures are contraindicated, and proper oral or intravenous hydration is the mainstay of treatment. ZIKV represents a concern because of sexual and vertical transmission, with the risk of microcephaly and other congenital malformations, but also with increased risk of Guillain-Barré syndrome [19]. Affected individuals have to be individually counseled to avoid sexual transmission, and affected pregnant women have to be advised about the possible fetal risk and appropriately monitored. CHIKV produces arthralgia often lasting for years, which requires anti-inflammatory, immunomodulatory or, sometimes, immunosuppressive treatment [20]. In the context of travel medicine, especially in countries such as Italy where competent vectors are widespread, a rapid diagnosis is essential to diagnose patients with Aedes-transmitted arbovirosis in order to perform preventive measures of vector elimination, with the aim of preventing the emergence of autochthonous foci [21-23].

Regarding diagnosis, during the first five to seven days from the onset of symptoms, the gold standard is represented by nucleic acid amplification tests (NAAT) to detect viral RNA. In the case of DENV, detection of non-structural protein 1 (NS1) is also possible either with enzyme-linked immunosorbent assay (ELISA) or rapid immunochromatographic test (ICT). After one week from the onset of symptoms, diagnosis relies on serodiagnostic tests, with seroconversion of IgG or at least four-fold increase of IgG titers using ELISA, indirect fluorescent antibody test (IFAT) or plaque reduction and neutralization test (PNRT) [24-26]. Rapid diagnostic tests are commercially available for these three infections. However, the performance of these tests is not the same for these three pathogens. For DENV, several rapid commercial tests with excellent performance are available to detect both the NS1 antigen (in the first 7 days of symptoms) and antibodies (after 5 days from symptoms onset), usually ensuring a rapid and reliable diagnosis, however, for CHIKV and ZIKV the reported performance of rapid commercial tests is often disappointing [27-29]. Recently, a rapid Loop-Mediated Isothermal Amplification Technique based test (RT-LAMP) has been described to detect ZIKV-RNA and DENV-RNA with high sensitivity [30,31].

The main aim of this study was to develop a score for the early identification of ZIKV, CHIKV and DENV imported arbovirus infections, based on anamnestic and laboratory findings in febrile ill travelers returning from an endemic country, which could be predictive for each of the three arbovirosis. Secondly, this study aims to find distinctive characteristics to differentiate each of the three arbovirosis described. 


\section{Materials and Methods}

\subsection{Study Design, Setting and Inclusion Criteria}

This was a retrospective, unmatched case-control study.

The study was carried out at the Infectious and Tropical Disease Unit of Careggi Hospital, a tertiary teaching hospital in Florence, Italy, in the period from 1 January 2014, to 31 December 2019.

We included all febrile subjects returning from the tropics referred to our outpatient or inpatient service (depending on the severity of their symptoms and comorbidities) for suspected imported arbovirosis. The inclusion criteria were as follows:

Fever at the time of the medical visit, or history of fever (measured axillary temperature above $37.5^{\circ} \mathrm{C}$ ) developed within 2 weeks after returning from a tropical or subtropical country endemic for at least one of the three arboviruses (DENV, and/or CHIKV, and/or ZIKV).

(1) presentation to the service no later than 2 weeks from the first day of fever

(2) being tested for DENV, and/or CHIKV, and/or ZIKV

We excluded patients diagnosed with malaria, as the disease was usually ruled out at the beginning of the diagnostic process in travelers returning from malarial areas through blood smear and/or molecular tests. The study was conducted under the provisions of the Declaration of Helsinki and in accordance with the International Conference on Harmonization Consolidated Guideline on Good Clinical Practice.

\subsection{Definitions}

To identify DENV, CHIKV, and ZIKV infection cases, we used the case definition proposed by the Italian Ministry of Health arbovirosis surveillance plan, published in 2020 [32]. According to these definitions, we included in the "case group" in our study only probable or confirmed cases. Detailed information about these definitions is reported in Supplementary Table S1.

In all febrile subjects returning from the tropics, molecular tests on serum and/or urinary and/or saliva samples were performed in case of the onset of symptoms from less than 7 days. Otherwise, serological tests (IgG and IgM) were performed. In the case of DENV, we also performed the antigen NS1 test within 7 days from the beginning of clinical symptoms. Detailed information about tests performed at our center is reported in Supplementary Table S2.

Controls were travelers with other febrile illnesses (OFIs) who tested negative in laboratory analysis for all three arboviruses.

For both cases and controls, main epidemiological and clinical data and laboratory values were collected in a database. A tourist was defined as any person who had crossed an international border to travel outside the country where they had settled; if the length of travel lasts more than 6 months, they are called expatriates. A migrant was defined as any person arriving in a country different from their own to settle in the new country. A traveler who had returned to their country of origin to visit relatives and/or friends was defined as a VRF.

We defined thrombocytopenia as below $140,000 / \mu \mathrm{L}$, leukopenia below $4000 / \mu \mathrm{L}$ and hypertransaminasemia as alanine aminotransferase $(\mathrm{ALT})>60 \mathrm{UI} / \mathrm{mL}$. C reactive protein $(\mathrm{CRP})$ was defined as normal if below $9 \mathrm{mg} / \mathrm{L}$.

\subsection{Variables and Statistical Approach}

We also collected clinical data regarding the most relevant presented signs and symptoms, as well as laboratory test results including counts of leukocytes, neutrophils and platelets, prothrombin time (PT), ALT and CRP values. Statistical analysis was made using STATA software (v. 14.0).

Continuous variables were summarized as medians and interquartile ranges (IQRs) and were compared using Mann-Whitney $U$ tests for two-group comparisons. Categorical variables were 
expressed as frequencies and percentages and were analyzed using Chi-squared or Fisher's exact tests, as appropriate. Leukocytes, platelets, and ALT values were also interpreted as categorical variables using the reference values available in our laboratory. A univariate logistic regression analysis was performed. Any variable with a $p$-value equal or inferior to 0.2 was considered potentially significant and was further analyzed in multivariate logistic regression (CRP and neutrophil count were excluded because they were available only for limited number of observations). Therefore, we created a simplified score based on the regression coefficients for the independent predictors. Specifically, as previously reported, we divided the smallest regression coefficient by the lowest factor in the model and rounded this quotient to the nearest whole number [33]. We assessed the performance of the score model with the area under the curve (AUC) of receiver operating characteristic (ROC) curve [34]. Therefore, we found the best cut-off by calculating the Youden Index.

\section{Results}

Detailed information about the selection process of cases and controls is described in the flow chart in Supplementary Figure S1.

The characteristics of controls and cases are summarized in Table 1.

Table 1. Clinical and demographic characteristics of cases: Chikungunya (CHIKV), Dengue (DENV), and Zika (ZIKV) infection cases, and controls (OFIs).

\begin{tabular}{|c|c|c|c|}
\hline & $\begin{array}{c}\text { Control } \\
N=56 \\
(\%)\end{array}$ & $\begin{array}{c}\text { Case } \\
N=34 \\
(\%)\end{array}$ & $p$-Value \\
\hline \multicolumn{4}{|l|}{ Gender } \\
\hline Male & $31(55.4)$ & $13(38.2)$ & 0.115 \\
\hline Female & $25(44.6)$ & $21(61.8)$ & \\
\hline \multicolumn{4}{|l|}{ Age in years } \\
\hline $15-29$ & $22(39.3)$ & $8(23.5)$ & \multirow{3}{*}{0.307} \\
\hline $30-49$ & $21(37.5)$ & $16(47.1)$ & \\
\hline $50-70$ & $13(23.2)$ & $10(29.4)$ & \\
\hline \multicolumn{4}{|l|}{ Region of Birth } \\
\hline Europe & $47(83.9)$ & $28(82.3)$ & \multirow{7}{*}{0.156} \\
\hline Sub-Saharan Africa & $4(7.1)$ & 0 & \\
\hline Middle South-Asia & $1(1.8)$ & $2(5.9)$ & \\
\hline South-East Asia & $1(1.8)$ & 0 & \\
\hline South America & $1(1.8)$ & $3(8.8)$ & \\
\hline North America & $2(3.6)$ & 0 & \\
\hline Central America & 0 & $1(2.9)$ & \\
\hline \multicolumn{4}{|l|}{ Cause of travel } \\
\hline Tourist & $49(87.5)$ & $31(91.2)$ & \multirow{3}{*}{0.856} \\
\hline Migrant & $2(3.6)$ & $1(2.9)$ & \\
\hline VRF & $5(8.9)$ & $2(5.9)$ & \\
\hline $\begin{array}{l}\text { Days between return and onset of symptoms } \\
\text { (median, IQR) }\end{array}$ & $1(0-4)$ & $1(0-4)$ & 0.426 \\
\hline Length of journey in days $\S$ & $15(10-21.5)$ & $15(11-21)$ & 0.896 \\
\hline
\end{tabular}


Table 1. Cont.

\begin{tabular}{|c|c|c|c|}
\hline & $\begin{array}{l}\text { Control } \\
N=56 \\
(\%)\end{array}$ & $\begin{array}{c}\text { Case } \\
N=34 \\
(\%)\end{array}$ & $p$-Value \\
\hline $\begin{array}{l}\text { Days between onset of symptoms and first } \mathrm{n} \\
\text { visit } \\
\text { (median, IQR) }\end{array}$ & $4(2-7)$ & $4.5(3-7)$ & 0.230 \\
\hline $\begin{array}{c}\text { Returning Continent } \\
\text { Sub-Saharan Africa } \\
\text { North Africa } \\
\text { Middle East } \\
\text { Middle-South Asia } \\
\text { Southeast Asia } \\
\text { South America } \\
\text { Central America } \\
\text { Oceania }\end{array}$ & $\begin{array}{c}13(23.2) \\
1(1.8) \\
1(1.8) \\
8(14.3) \\
21(37.5) \\
6(10.7) \\
6(10.7) \\
0\end{array}$ & $\begin{array}{c}1(2.9) \\
0 \\
0 \\
4(11.8) \\
10(29.4) \\
6(17.6) \\
12(35.3) \\
1(2.9)\end{array}$ & 0.024 \\
\hline People returning from Africa & $14(25.0)$ & $1(2.9)$ & 0.006 \\
\hline Myalgia & $17(30.4)$ & $21(61.8)$ & 0.003 \\
\hline Rachialgia & $14(25.0)$ & $13(38.2)$ & 0.184 \\
\hline Headache & $28(50.0)$ & $17(50.0)$ & 1.000 \\
\hline Retro-orbital pain & $6(10.7)$ & $12(35.3)$ & 0.005 \\
\hline Conjunctival hyperaemia & $2(3.6)$ & $7(20.6)$ & 0.009 \\
\hline Gastrointestinal symptoms * & $19(33.9)$ & $11(32.3)$ & 0.878 \\
\hline Respiratory symptoms ** & $26(46.4)$ & $6(17.6)$ & 0.006 \\
\hline Disgeusia & 0 & $5(14.7)$ & 0.003 \\
\hline Rash & $8(14.3)$ & $23(67.6)$ & 0.000 \\
\hline Arthritis & 0 & $4(11.8)$ & 0.009 \\
\hline Arthralgia & $13(23.2)$ & $10(29.4)$ & 0.513 \\
\hline Leukocytes/mcL, median (IQR) & $\begin{array}{c}6365 \\
(4925-9310)\end{array}$ & $\begin{array}{c}3725 \\
(2360-5340)\end{array}$ & 0.000 \\
\hline Leukopenia $<4000 / \mathrm{mcL}$ & $4(7.1)$ & $20(58.8)$ & 0.000 \\
\hline Neutrophil count $\S \S$ median (IQR) & $\begin{array}{c}3710 \\
(2850-6310) \S\end{array}$ & $\begin{array}{c}2146.5 \\
(1245-3360) \S\end{array}$ & 0.000 \\
\hline Platelets $\times 10^{3} / \mathrm{mcL}$, median (IQR) & $187(148-236.5)$ & $\begin{array}{c}145.5 \\
(108-183)\end{array}$ & 0.010 \\
\hline Thrombocytopenia $<140.000 / \mathrm{mcL}$ & $11(19.6)$ & $13(38.2)$ & 0.053 \\
\hline ALT $>60 \mathrm{U} / \mathrm{L}$ & $11(19.6)$ & $12(35.3)$ & 0.099 \\
\hline ALT (U/L) median (IQR) & $33.5(24-49)$ & $34.5(23-91)$ & 0.516 \\
\hline $\mathrm{CRP}>9 \mathrm{mg} / \mathrm{L} \S \S \S$ & $34(70.8) \S \S$ & $8(33.3) \S \S$ & 0.002 \\
\hline
\end{tabular}

Footnotes: VRF, visiting relatives and friends; IQR, interquartile range; ALT, alanine transaminase; CRP, C-reactive protein. * At least one of the following: nausea, vomiting, diarrhea. ${ }^{* *}$ At least one the following: coughing, respiratory distress, sore throat, rinorrhea. § data on 82 observations (30 cases and 52 controls) $\S \S$ Data on 83 observations ( 32 cases and 51 controls). $\S \S \S$ Data on 72 observations ( 24 cases and 48 controls).

Overall, 90 patients were identified from a database: 34 cases and 56 controls. Among the cases, 22 were diagnosed with DENV infection (20 confirmed and 2 probable cases), 8 with ZIKV infection (all confirmed), and 4 with CHIKV infection (all confirmed). Diagnostic results are listed in Supplementary Table S3. Fourteen cases $(41.2 \%)$ and 24 controls $(42.9 \%)$ were hospitalized. No patients included in the study had dual or triple co-infections. Among cases, the majority were females 
( $n=21,61.8 \%$ ), and the median age was 38.5 years (IQR 33-48). Among controls, we had 31 males $(55.4 \%)$, and the median age was 33 years (IQR 28-47). Italy was the most represented country of birth among cases $(n=28)$ and controls $(n=47)$. Tourists were the majority of controls $(n=49)$ and cases $(n=31)$. We did not find any expatriates among cases and controls. Most cases came from Central America ( $n=12,35.3 \%)$, whereas most patients with OFIs came from Southeast Asia $(n=21,37.5 \%)$. We had a single case coming from Africa (Seychelles). Among cases, the most common presented signs and symptoms were a cutaneous rash $(n=23,67.6 \%)$ and myalgia $(n=21,61.8 \%)$. Regarding controls, they most commonly presented respiratory symptoms $(n=26,46.4 \%)$ or gastrointestinal problems $(n=19,33.9 \%)$. Concerning laboratory results, case-patients most commonly presented thrombocytopenia $(n=13,38.2 \%)$ and leukopenia $(n=20,58.8 \%)$. Hypertransaminasemia was found in 12 cases (35.3\%). Returning from Africa resulted in a negative association with ZIKV, CHIKV and DENV infections, although this association was statistically weak.

In Table 2, we report the characteristics of different arbovirosis.

Table 2. Clinical and demographic characteristics of DENV, CHIKV and ZIKV arbovirosis.

\begin{tabular}{|c|c|c|c|}
\hline & $\begin{array}{c}\text { DENV } \\
N=22(\%)\end{array}$ & $\begin{array}{c}\text { CHIKV } \\
N=4(\%)\end{array}$ & $\begin{array}{c}\text { ZIKV } \\
N=8(\%)\end{array}$ \\
\hline \multicolumn{4}{|l|}{ Gender } \\
\hline Male & $9(40.9)$ & $1(25.0)$ & $3(37.5)$ \\
\hline Female & $13(59.1)$ & $3(75.0)$ & $5(62.5)$ \\
\hline \multicolumn{4}{|l|}{ Age in years } \\
\hline $15-29$ & $5(22.7)$ & 0 & $3(37.5)$ \\
\hline $30-49$ & $10(45.4)$ & $2(50.0)$ & $4(50.0)$ \\
\hline $50-70$ & $7(31.8)$ & $2(50.0)$ & $1(12.5)$ \\
\hline \multicolumn{4}{|l|}{ Continent of Birth } \\
\hline Europe & $19(86.4)$ & $1(25.0)$ & $8(100.0)$ \\
\hline Middle-South Asia & $2(9.1)$ & 0 & 0 \\
\hline South America & 0 & $3(75.0)$ & 0 \\
\hline Central America & $1(4.5)$ & 0 & 0 \\
\hline \multicolumn{4}{|l|}{ Returning continent } \\
\hline Sub-Saharan Africa & $1(4.5)$ & 0 & 0 \\
\hline Middle-South Asia & $4(18.2)$ & 0 & 0 \\
\hline Southeast Asia & $9(40.9)$ & 0 & $1(12.5)$ \\
\hline South America & $2(9.1)$ & $2(50.0)$ & $2(25.0)$ \\
\hline Central America & $6(27.3)$ & $2(50.0)$ & $4(50.0)$ \\
\hline Oceania & 0 & 0 & $1(12.5)$ \\
\hline Myalgia & $17(77.3)$ & 0 & $4(50.0)$ \\
\hline Rachialgia & $10(45.4)$ & $1(25.0)$ & $2(25.0)$ \\
\hline Retro-orbital pain & $8(36.4)$ & 0 & $4(50.0)$ \\
\hline Conjunctival hyperaemia & $1(4.5)$ & $2(50.0)$ & $4(50.0)$ \\
\hline Gastrointestinal symptoms * & $9(40.9)$ & $2(50.0)$ & 0 \\
\hline Respiratory symptoms ** & $4(18.2)$ & $1(25.0)$ & $1(12.5)$ \\
\hline Disgeusia & $5(22.7)$ & 0 & 0 \\
\hline
\end{tabular}


Table 2. Cont.

\begin{tabular}{|c|c|c|c|}
\hline & $\begin{array}{c}\text { DENV } \\
N=22(\%)\end{array}$ & $\begin{array}{c}\text { CHIKV } \\
N=4(\%)\end{array}$ & $\begin{array}{c}\text { ZIKV } \\
N=8(\%)\end{array}$ \\
\hline Rash & $11(50.0)$ & $4(100.0)$ & $8(100.0)$ \\
\hline Arthritis & 0 & $3(75.0)$ & $1(12.5)$ \\
\hline Arthralgia & $3(13.6)$ & $4(100)$ & $3(37.5)$ \\
\hline Leukocytes/mcL median (IQR) & $3090(2120-3910)$ & $5240(3645-6590)$ & $4450(3985-7195)$ \\
\hline Leukopenia < 4000/mcL & $17(77.3)$ & $1(25.0)$ & $2(25.0)$ \\
\hline Neutrophil count $\S$ median [IQR] & $1418(965-2700) \S$ & $2970(1975-3755) \S$ & $2540(2146-4194) \S$ \\
\hline Thrombocytopenia $<140.000 / \mathrm{mcL}$ & $10(45.4)$ & 0 & $3(37.5)$ \\
\hline Platelets $\times 10^{3} / \mathrm{mcL}$ median (IQR) & $142(88-169)$ & $349.5(278-414.5)$ & $158(137-175.5)$ \\
\hline $\mathrm{ALT}>60 \mathrm{U} / \mathrm{L}$ & $11(50.0)$ & $1(25.0)$ & 0 \\
\hline ALT (U/L) median [IQR] & $60(25-105)$ & $40(19.5-65.5)$ & $21(15.5-31)$ \\
\hline $\mathrm{CRP}>9 \mathrm{mg} / \mathrm{L} \S \S$ & $5(29.4) \S \S$ & $2(66.7) \S \S$ & $1(25.0)$ \\
\hline
\end{tabular}

Footnotes: DENV, Dengue virus; CHIKV, Chikungunya virus; ZIKV, Zika virus; ALT, alanine transaminase; CRP, $\mathrm{C}$-reactive protein. * We considered gastrointestinal symptoms to be the presence of at least one of the following: nausea, vomiting, diarrhea. ${ }^{* *}$ We considered respiratory symptoms the presence of at least one the following: coughing, respiratory distress, sore throat, rhinorrhea. § Data on 32 observations (20 DENV, 4 CHIKV, 8 ZIKV). $\S \S$ Data on 24 observations (17 DENV, 3 CHIKV, 4 ZIKV).

Regarding DENV infection, myalgia $(n=17,77.3 \%)$ was the most common symptom, and leukopenia $(n=17,77.3 \%)$ was the most common laboratory finding. Interestingly, there was only one case of severe dengue, which also presented leukocytosis $(29,800 / \mu \mathrm{L})$. Arthralgia and arthritis were the most common clinical features present in CHIKV infections, in $100 \%$ and $75 \%$ of patients, respectively. The most frequent symptoms of ZIKV patients were rash $(100 \%)$ and headache $(75 \%)$. Regarding the number of neutrophils, the median value resulted smaller in DENV infection $(1418 / \mu \mathrm{L})$. CRP was positive in 8 of 24 tested cases $(33.3 \%)$ : the highest value $(189 \mathrm{mg} / \mathrm{dL})$ was registered in the case of severe dengue, where no bacterial superinfection was demonstrated. Among cases with hypertransaminasemia, 11 (91.7\%) were DENV infections; there were no ZIKV patients presenting with ALT elevation. Median platelet level was higher in CHIKV $\left(349 \times 10^{3} / \mathrm{mcL}\right)$ than DENV $\left(142 \times 10^{3} / \mathrm{mcL}\right)$ and ZIKV $\left(158 \times 10^{3} / \mathrm{mcL}\right)$. According to our multivariate analysis, myalgia, rash, absence of respiratory symptoms, leukopenia and hypertransaminasemia showed the strongest association with arbovirosis (Table 3).

Table 3. Multivariable model and risk score for arbovirosis.

\begin{tabular}{ccccc}
\hline Variables & OR $\left._{\mathbf{a}} \mathbf{( 9 5} \% \mathbf{C I}\right)$ & $p$ & Regression Coefficient & Risk Score Weight \\
\hline Rash & $23.46(2.79-196.88)$ & 0.004 & 3.15 & 1 \\
Thrombocytopenia & $0.47(0.06-3.55)$ & 0.463 & -0.76 & na \\
Leukopenia & $54.93(4.56-661.57)$ & 0.002 & 4.01 & 2 \\
Hypertransaminasemia & $9.41(1.23-71.66)$ & 0.031 & 2.24 & 1 \\
People returning from Africa & $0.04(0.00-12.18)$ & 0.278 & -3.10 & na \\
Retro-orbital pain & $2.82(0.35-22.90)$ & 0.331 & 1.04 & na \\
Conjunctival hyperemia & $0.80(0.07-9.52)$ & 0.862 & -0.22 & na \\
Myalgia & $13.48(1.97-92.17)$ & 0.008 & 2.60 & -1 \\
Respiratory symptoms & $0.10(0.01-0.74)$ & 0.024 & -2.26 & -1 \\
\hline
\end{tabular}

Footnotes: na, not applicable.

Therefore, using regression coefficients, we generated a scoring model including +2 points for leukopenia, +1 point for hypertransaminasemia, +1 point for rash, and +1 point for myalgia and 
-1 point for respiratory symptoms. The receiver operating characteristics (ROC) curve showed an AUC of 0.93 (Figure 1).

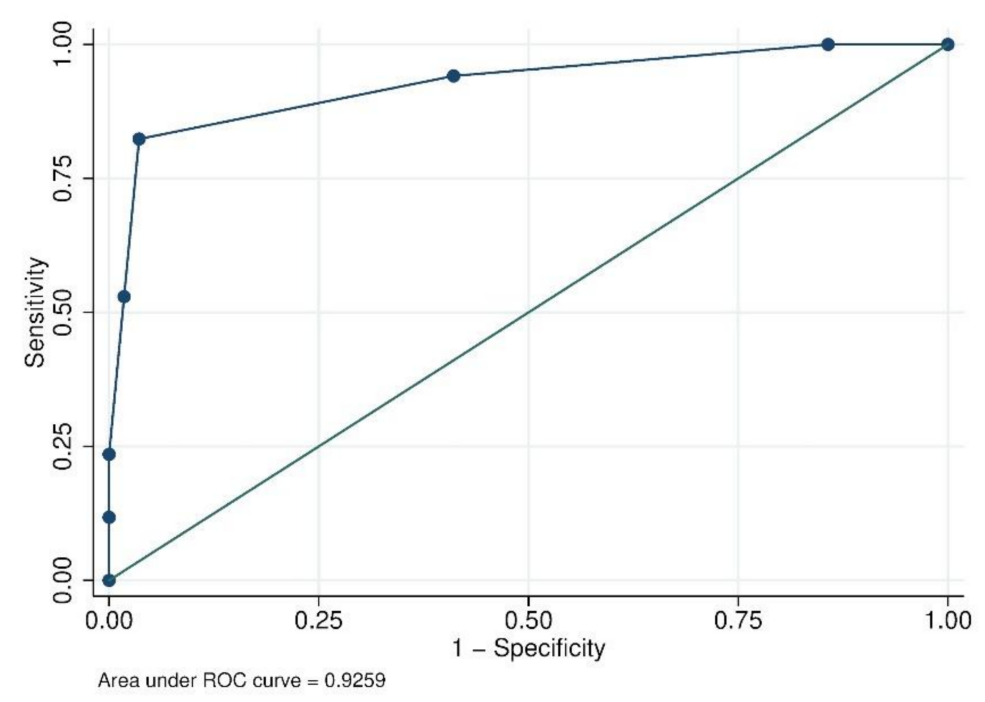

Figure 1. Receiver operating characteristics (ROC) curve for the score model with leukopenia, hypertransaminasemia, myalgia, rash, respiratory symptoms $(b / w)$.

The best cut-off point resulted in greater than or equal to 2 (Table 4).

Table 4. Youden index, sensitivity, and specificity of different cut-off points of a score for the early identification of imported arbovirosis infections in febrile ill travelers returning from an endemic country, based on three clinical signs (myalgia +1 point, rash +1 point, respiratory symptoms -1 point) and two laboratory values (leukopenia +2 points, hypertransaminasemia +1 point).

\begin{tabular}{cccc}
\hline Cut-off Point & Sensibility (\%) & Specificity (\%) & Youden Index \\
\hline$\geq-1$ & 100.00 & 0.00 & 0 \\
$\geq 0$ & 100.00 & 14.29 & 0.14 \\
$\geq 1$ & 94.12 & 58.93 & 0.53 \\
$\geq 2$ & 82.35 & 96.43 & 0.79 \\
$\geq 3$ & 52.94 & 98.21 & 0.51 \\
$\geq 4$ & 23.53 & 100.00 & 0.23 \\
$\geq 5$ & 11.76 & 100.00 & 0.12 \\
$>5$ & 0 & 100.00 & 0 \\
\hline
\end{tabular}

\section{Discussion}

Physicians who manage febrile, returning travelers must always place priority on the differential diagnosis of conditions that are treatable, that may cause serious sequelae or death, and pose a risk to public health [35]. Arbovirosis fulfills all the aforementioned priority conditions. A subject returning from an endemic area represents a risk for the emergence of autochthonous cases in areas where competent vectors are present; hence, an appropriate diagnostic approach is crucial to limit this risk. Very recently, small clusters of autochthonous DENV infection have been reported in northeast Italy and southern France, highlighting that, despite current travel limitations imposed by the COVID-19 pandemic, imported arbovirosis may still represent a challenge for clinicians and public health officers in temperate regions [36-39]. In 2016, researchers from Lausanne Infectious Disease Unit proposed one diagnostic algorithm for travelers with nonspecific febrile illnesses returning from regions experiencing simultaneous outbreaks of DENV, CHIKV, and ZIKV infections, based on serology results [40]. In our opinion, this approach could present some limitations. Firstly, serology in the first week from the onset of symptoms could be negative. Secondly, NAAT and serological ELISA tests could 
be available only in referral centers [41]. Therefore, patients who have been previously vaccinated for another Flavivirus such as Yellow Fever Virus, Japanese Encephalitis Virus, and Tick-borne Encephalitis Virus, could present false positive serology for DENV or ZIKV. Considering that the cost of routine surveillance preventive measures, such as comprehensive larviciding, over whole urban areas could overcome health benefits, especially in larger municipalities, rapid identification of imported arboviral infections is crucial to rapidly activate preventive measures localized in a specific area to avoid local transmission [42]. Regarding DENV infection, another aspect to consider is the variability of the viremic period, which could last on average nine days in travelers after the onset of symptoms, compared to seven days in endemic settings [43]. At the same time, the extrinsic incubation period (EIP) in competent vector mosquitos, generally referenced to be $8-12$ days, could be more variable and inversely correlated with temperature [44]. In a study published in 2019, lower leukocyte and platelet levels resulted in significant associations with DENV, CHIKV, and ZIKV in the differential diagnosis of imported fever [45].

According to our results, leukopenia, cutaneous rash, hypertransaminasemia, respiratory symptoms (at least one among cough, respiratory distress, sore throat and rhinorrhea) and myalgia were the best parameters to predict arbovirosis in a febrile traveler returning from a tropical country. A simple score, called ARBO-SCORE, based on three clinical data values v(myalgia, cutaneous rash and absence of respiratory symptoms) and two easily obtainable laboratory results (leukopenia and hypertransaminasemia), has been shown to provide a useful tool to help diagnose arboviral infections and to effectively activate vector control measures in order to avoid local transmission, with an accuracy of $91 \%$. The score we generated is straightforward and applicable in peripheral centers. Using our best cut-off point, we obtained a sensitivity of $82.35 \%$ and specificity of $96.43 \%$. Regarding different arbovirosis, it is important to emphasize that our case of severe dengue presented leucocitosis, which is a parameter prognostic for this disease [46]. Therefore, there was a notably different median for the platelet count: in a previous study, a lower platelet level was considered to be a prognostic value for DENV versus CHIKV [47]. The differences among these three arbovirosis reflect distinctive characteristics already previously described [48]. The study has several limitations. We excluded many patients because of a lack of information about clinical history or laboratory data. Selection biases could have been additional limitations in this study design. Cases and controls were not matched, so sex and age distribution were different in the two groups. Most cases were DENV infections (64.7\%). Presence or history of fever could have limited the number of ZIKV cases. In fact, we excluded three afebrile ZIKV cases. We did not perform any statistical analysis to differentiate among the three arbovirosis, because we estimated too small a number of cases.

\section{Conclusions}

We elaborated a predictive score named ARBO-SCORE based on three clinical signs (myalgia, rash and respiratory symptoms) and two laboratory values (leukopenia and hypertransaminasemia). The score showed an excellent performance in our population (AUC 0.93), but another validation cohort is necessary to confirm its predictive value. This score could be performed as soon as suspected febrile travelers are encountered, due to its straightforward nature. Therefore, the score is not meant to replace traditional tests for diagnosis, but could help to appropriately activate surveillance systems and perform preventive measures against vectors to avoid autochthonous cases. Further studies are necessary to find clinical predictive scores for each of these arbovirosis.

Supplementary Materials: The following are available online at http://www.mdpi.com/2076-2607/8/11/1731/s1: Figure S1: Flow chart of the selection process of cases and controls; Table S1: Definition of possible, probable and confirmed CHIK, DENV and ZIKV cases according to the 2020-2025 Italian National arbovirosis prevention and surveillance plan; Table S2: DENV, CHIKV, ZIKV serological test performed at Careggi University Hospital, Florence, Italy; Table S3: Diagnostic results of cases. 
Author Contributions: Conceptualization, L.Z.; Methodology, F.L.; Software, F.L.; Validation, F.L. and L.Z.; Formal Analysis, F.L.; Investigation, I.V.; Resources, A.M.; Data Curation, I.V.; Writing-Original Draft Preparation, I.V.; Writing-Review and Editing M.S., E.M., G.C., M.G.C., F.G., G.M.R. and A.B.; Visualization, I.V.; Supervision, L.Z.; Project Administration, L.Z. All authors have read and agreed to the published version of the manuscript.

Funding: This article has been supported by funds of the "Ministry of Education, University and Research (Italy) Excellence Departments 2018-2022" Project for the Department of Experimental and Clinical Medicine, University of Florence, Florence, Italy.

Conflicts of Interest: The authors declare no conflict of interest.

\section{References}

1. Priyamvada, L.; Quicke, K.M.; Hudson, W.H.; Onlamoon, N.; Sewatanon, J.; Edupuganti, S.; Pattanapanyasat, K.; Chokephaibulkit, K.; Mulligan, M.J.; Wilson, P.C.; et al. Human antibody responses after dengue virus infection are highly cross-reactive to Zika virus. Proc. Natl. Acad. Sci. USA 2016, 113, 7852-7857. [CrossRef] [PubMed]

2. Abhishek, K.S.; Chakravarti, A. Simultaneous detection of IgM antibodies against dengue and chikungunya: Coinfection or cross-reactivity? J. Fam. Med. Prim. Care 2019, 8, 2420-2423. [CrossRef]

3. Patterson, J.; Sammon, M.; Garg, M. Dengue, Zika and Chikungunya: Emerging arboviruses in the New World. West J. Emerg. Med. 2016, 17, 671-679. [CrossRef]

4. World Health Organization/Department of Control of Neglected Tropical Diseases and TDR. Dengue: Guidelines for Diagnosis, Treatment, Prevention and Control; World Health Organization: Geneva, Switzerland, 2009; ISBN 978-92-4-154787-1.

5. Graham, B.S.; Repik, P.M.; Yactayo, S. Chikungunya in the Americas: Recommendations and conclusions. J. Infect. Dis. 2016, 214, 510-513. [CrossRef]

6. Duffy, M.R.; Chen, T.H.; Hancock, W.T.; Powers, A.M.; Kool, J.L.; Lanciotti, R.S.; Pretrick, M.; Marfel, M.; Holzbauer, S.; Dubray, C.; et al. Zika virus outbreak on Yap Island, Federated States of Micronesia. N. Engl. J. Med. 2009, 360, 2536-2543. [CrossRef] [PubMed]

7. Vega, F.L.R.; Bezerra, J.M.T.; Said, R.F.C.; Gama Neto, A.N.D.; Cotrim, E.C.; Mendez, D.; Amâncio, F.F.; Carneiro, M. Emergence of chikungunya and Zika in a municipality endemic to dengue, Santa Luzia, MG, Brazil, 2015-2017. Revista Sociedade Brasileira Medicina Tropical 2019, 52, e20180347. [CrossRef] [PubMed]

8. Fortuna, C.; Remoli, M.E.; Rizzo, C.; Benedetti, E.; Fiorentini, C.; Bella, A.; Argentini, C.; Farchi, F.; Castilletti, C.; Capobianchi, M.R.; et al. Imported arboviral infections in Italy, July 2014-October 2015: A national reference laboratory report. BMC Infect. Dis. 2017, 17, 216. [CrossRef]

9. Añez, G.; Rios, M. Dengue in the United States of America: A worsening scenario? BioMed Res. Int. 2013, 2013, 678645. [CrossRef]

10. Succo, T.; Leparc Goffart, I.; Ferré, J.B.; Roiz, D.; Broche, B.; Maquart, M.; Noel, H.; Catelinois, O.; Entezam, F.; Caire, D.; et al. Autochthonous dengue outbreak in Nîmes, South of France, July to September 2015. Eurosurveillance 2016, 21. [CrossRef] [PubMed]

11. Rezza, G. Chikungunya is back in Italy: 2007-2017. J. Travel Med. 2018, 25. [CrossRef] [PubMed]

12. European Centre for Disease prevention and Control. Autochthonous Cases of Dengue in Spain and France; European Centre for Disease Prevention and Control (ECDC): Stockholm, Sweden, 2019.

13. Angelo, K.M.; Stoney, R.J.; Brun Cottan, G.; Leder, K.; Grobusch, M.P.; Hochberg, N.; Kuhn, S.; Bottieau, E.; Schlagenhauf, P.; Chen, L.; et al. Zika among international travellers presenting to GeoSentinel sites, 2012-2019: Implications for clinical practice. J. Travel Med. 2020, 27, taaa061. [CrossRef]

14. European Centre for Disease Prevention and Control. Zika Virus Disease in Var department, France; European Centre for Disease Prevention and Control (ECDC): Stockholm, Sweden, 2019.

15. Sabino, E.C.; Loureiro, P.; Lopes, M.E.; Capuani, L.; McClure, C.; Chowdhury, D.; Di-Lorenzo Oliveira, C.; Oliveira, L.C.; Linnen, J.M.; Lee, T.H.; et al. International component of the NHLBI recipient epidemiology and donor evaluation Study-III. transfusion-transmitted Dengue and associated clinical symptoms during the 2012 epidemic in Brazil. J. Infect. Dis. 2016, 213, 694-702. [CrossRef]

16. Venturi, G.; Zammarchi, L.; Fortuna, C.; Remoli, M.E.; Benedetti, E.; Fiorentini, C.; Trotta, M.; Rizzo, C.; Mantella, A.; Rezza, G.; et al. An autochthonous case of Zika due to possible sexual transmission, Florence, Italy, 2014. Eurosurveillance 2016, 21, 30148. [CrossRef] 
17. European Centre for Disease Prevention and Control. Sexual Transmission of Dengue in Spain; European Centre for Disease Prevention and Control (ECDC): Stockholm, Sweden, 2019.

18. Lagi, F.; Zammarchi, L.; Strohmeyer, M.; Bartalesi, F.; Mantella, A.; Meli, M.; Blanc, P.; Tacconi, D.; Farese, A.; Zanelli, G.; et al. Imported dengue fever in Tuscany, Italy, in the period 2006 to 2012. J. Travel Med. 2014, 21, 340-343. [CrossRef] [PubMed]

19. Zammarchi, L.; Spinicci, M.; Bartoloni, A. Zika Virus: A review from the virus basics to proposed management strategies. Mediterr. J. Hematol. Infect. Dis. 2016, 8, e2016056. [CrossRef]

20. Paixão, E.S.; Rodrigues, L.C.; Costa, M.D.C.N.; Itaparica, M.; Barreto, F.; Gérardin, P.; Teixeira, M.G. Chikungunya chronic disease: A systematic review and meta-analysis. Trans. R. Soc. Trop. Med. Hyg. 2018, 112, 301-316. [CrossRef]

21. Viennet, E.; Ritchie, S.A.; Williams, C.R.; Faddy, H.M.; Harley, D. Public health responses to and challenges for the control of Dengue transmission in high-income countries: Four case studies. PLoS Negl. Trop. Dis. 2016, 10, e0004943. [CrossRef] [PubMed]

22. Millet, J.P.; Montalvo, T.; Bueno Marí, R.; Romero Tamarit, A.; Prats Uribe, A.; Fernández, L.; Camprubí, E.; Del Baño, L.; Peracho, V.; Figuerola, J.; et al. Zika working group in Barcelona. Imported Zika virus in a European city: How to prevent local transmission? Front. Microbiol. 2017, 8, 1319. [CrossRef]

23. Gobbi, F.; Capelli, G.; Angheben, A.; Giobbia, M.; Conforto, M.; Franzetti, M.; Cattelan, A.M.; Raise, E.; Rovere, P.; Mulatti, P.; et al. Summer fever study group. Human and entomological surveillance of West Nile fever, Dengue and Chikungunya in Veneto Region, Italy, 2010-2012. BMC Infect. Dis. 2014, 14, 60. [CrossRef]

24. Natrajan, M.S.; Rojas, A.; Waggoner, J.J. Beyond fever and pain: Diagnostic methods for Chikungunya virus. J. Clin. Microbiol. 2019, 57, e00350-19. [CrossRef]

25. Theel, S.; Hata, D.J. Diagnostic testing for Zika virus: A postoutbreak update. J. Clin. Microbiol. 2018, 56, e01972. [CrossRef]

26. Rodriguez Manzano, J.; Chia, P.Y.; Yeo, T.W.; Holmes, A.; Georgiou, P.; Yacoub, S. Improving Dengue diagnostics and management through innovative technology. Curr. Infect. Dis. Rep. 2018, 20, 25. [CrossRef] [PubMed]

27. Zammarchi, L.; Colao, M.G.; Mantella, A.; Capobianco, T.; Mazzarelli, G.; Ciccone, N.; Tekle Kiros, S.; Mantengoli, E.; Rossolini, G.M.; Bartoloni, A. Evaluation of a new rapid fluorescence immunoassay for the diagnosis of dengue and Zika virus infection. J. Clin. Virol. 2019, 112, 34-39. [CrossRef] [PubMed]

28. Magurano, F.; Zammarchi, L.; Baggieri, M.; Fortuna, C.; Farese, A.; Benedetti, E.; Fiorentini, C.; Rezza, G.; Nicoletti, L.; Bartoloni, A. Chikungunya from the Caribbean: The importance of appropriate laboratory tests to confirm the diagnosis. Vector Borne Zoonotic Dis. 2015, 15, 258-260. [CrossRef] [PubMed]

29. Andries, A.C.; Duong, V.; Ngan, C.; Ong, S.; Huy, R.; Sroin, K.K.; Te, V.; Bunthin, Y.; Try, P.L.; Buchy, P. Field evaluation and impact on clinical management of a rapid diagnostic kit that detects dengue NS1, IgM and IgG. PLoS Negl. Trop. Dis 1993, 6, e1993. [CrossRef]

30. Estrela, P.F.N.; Mendes, G.M.; De Oliveira, K.G.; Bailão, A.M.; Soares, C.M.A.; Assunção, N.A.; Duarte, G.R.M. Ten-minute direct detection of Zika virus in serum samples by RT-LAMP. J. Virol. Methods 2019, 271, 113675. [CrossRef]

31. Hu, S.F.; Li, M.; Zhong, L.L.; Lu, S.M.; Liu, Z.X.; Pu, J.Y.; Wen, J.S.; Huang, X. Development of reverse-transcription loop-mediated isothermal amplification assay for rapid detection and differentiation of dengue virus serotypes 1-4. BMC Microbiol. 2015, 15, 265. [CrossRef]

32. Italian Ministry of Health. 2020-2025 Italian National Arboviroses Prevention and Surveillance Plan. Available online: http://www.statoregioni.it/media/2371/p-1-csr-rep-n-1-15gen2020.pdf (accessed on 23 June 2020).

33. Sullivan, L.M.; Massaro, J.M.; D'Agostino, R.B. Presentation of multivariate data for clinical use: The Framingham study risk score functions. Stat. Med. 2004, 23, 1631-1660. [CrossRef]

34. Zweig, M.H.; Campbell, G. Receiver-operating characteristic (ROC) plots: A fundamental evaluation tool in clinical medicine. Clin. Chem. 1993, 39, 561-577. [CrossRef]

35. Wilson, M. Fever in returned travelers. In Travel Medicine, 2nd ed.; Keystone, J., Kozarsky, P.E., Freedman, D.O., Nothdurft, H.D., Connor, B.A., Eds.; Elsevier: Philadelphia, PA, USA, 2008; pp. 513-521. ISBN 978-0-323-03453-1. 
36. Lazzarini, L.; Barzon, L.; Foglia, F.; Manfrin, V.; Pacenti, M.; Pavan, G.; Rassu, M.; Capelli, G.; Montarsi, F.; Martini, S.; et al. First autochthonous dengue outbreak in Italy, August 2020. Eurosurveillance 2020, 25. [CrossRef]

37. Vermeulen, T.D.; Reimerink, J.; Reusken, C.; Giron, S.; de Vries, P.J. Autochthonous dengue in two Dutch tourists visiting Département Var, southern France, July 2020. Eurosurveillance 2020, 25. [CrossRef]

38. Mary, E.; Wilson, M.D.; Chen, L.H. Re-starting travel in the era of COVID-19: Preparing anew. J. Travel Med. 2020, 27, taaa108. [CrossRef]

39. Spinicci, M.; Bartoloni, A.; Mantella, A.; Zammarchi, L.; Rossolini, G.M.; Antonelli, A. Low risk of serological cross-reactivity between dengue and COVID-19. Memórias Instituto Oswaldo Cruz 2020, 115, e200225. [CrossRef] [PubMed]

40. Moulin, E.; Selby, K.; Cherpillod, P.; Kaiser, L.; Boillat Blanco, N. Simultaneous outbreaks of dengue, chikungunya and Zika virus infections: Diagnosis challenge in a returning traveller with nonspecific febrile illness. New Microbes New Infect. 2016, 11, 6-7. [CrossRef]

41. Tilli, M.; Botta, A.; Bartoloni, A.; Corti, G.; Zammarchi, L. Hospitalization for Chagas disease, dengue, filariasis, leishmaniasis, schistosomiasis, strongyloidiasis, and Taenia solium taeniasis/cysticercosis, Italy, 2011-2016. Infection 2020, 48, 695-713. [CrossRef] [PubMed]

42. Guzzetta, G.; Trentini, F.; Poletti, P.; Baldacchino, F.A.; Montarsi, F.; Capelli, G.; Rizzoli, A.; Rosà, R.; Merler, S.; Melegaro, A. Effectiveness and economic assessment of routine larviciding for prevention of chikungunya and dengue in temperate urban settings in Europe. PLoS Negl. Trop. Dis. 2017, 11, e0005918. [CrossRef]

43. Erra, E.O.; Korhonen, E.M.; Voutilainen, L.; Huhtamo, E.; Vapalahti, O.; Kantele, A. Dengue in travelers: Kinetics of viremia and NS1 antigenemia and their associations with clinical parameters. PLoS ONE 2013, 8, e65900. [CrossRef]

44. Chan, M.; Johansson, M.A. The incubation periods of Dengue viruses. PLoS ONE 2012, 7, e50972. [CrossRef] [PubMed]

45. Rubio, E.; Alejo, C.I.; Aylagas, C.; Camprubí, D.; Ferré, R.; Albarracín, M.R.; Gonzalo, V.; Barrachina, J.; Álvarez, M.M.J.; Valls, M.E.; et al. Diagnostic value of Platelet and Leukocyte counts in the differential diagnosis of fever in the returning traveler. Am. J. Trop. Med. Hyg. 2019, 100, 470-475. [CrossRef]

46. Lee, I.K.; Liu, J.W.; Chen, Y.H.; Chen, Y.C.; Tsai, C.Y.; Huang, S.Y.; Lin, C.Y.; Huang, C.H. Development of a simple clinical risk score for early prediction of severe Dengue in adult patients. PLOS ONE 2016, 11, e0154772. [CrossRef]

47. Lee, V.J.; Chow, A.; Zheng, X.; Carrasco, L.R.; Cook, A.R.; Lye, D.C.; Ng, L.C.; Leo, Y.S. Simple clinical and laboratory predictors of Chikungunya versus dengue infections in adults. PLoS Negl. Trop. Dis. 2012, 6, e1786. [CrossRef] [PubMed]

48. Eckerle, I.; Briciu, V.T.; Ergönül, Ö.; Lupşe, M.; Papa, A.; Radulescu, A.; Tsiodras, S.; Tsitou, C.; Drosten, C.; Nussenblatt, V.R.; et al. Emerging souvenirs-clinical presentation of the returning traveller with imported arbovirus infections in Europe. Clin. Microbiol. Infect. 2018, 24, 240-245. [CrossRef]

Publisher's Note: MDPI stays neutral with regard to jurisdictional claims in published maps and institutional affiliations.

(C) 2020 by the authors. Licensee MDPI, Basel, Switzerland. This article is an open access article distributed under the terms and conditions of the Creative Commons Attribution (CC BY) license (http://creativecommons.org/licenses/by/4.0/). 